\title{
LABEL CO-MOVEMENT: COMPONENT STOCK INCLUSION AND EXCLUSION BETWEEN DIFFERENT EXCHANGE-TRADED FUNDS
}

\author{
Chun-An Li, National Yunlin University of Science and Technology \\ Min-Ching Lee, National Yunlin University of Science and Technology \\ Ju-Hua Liu, National Yunlin University of Science and Technology
}

\begin{abstract}
This study examines the co-movement phenomenon in Taiwan's stock markets. We investigate this phenomenon both before and after the inclusion and exclusion of component stocks from the Taiwan 50 or Taiwan 100 indices in terms of changes in component stock returns and turnover co-movement relationships. In addition to providing a sample analysis, this study explores consistency in changes to comovement relationships owing to market status (bull or bear) or investor sentiment (overly optimistic, optimistic, pessimistic, and overly pessimistic). The empirical results reflect the stocks' returns or turnover. For example, apart from periods of overly pessimistic sentiment, including and excluding components in the Taiwan 100 or Taiwan 50 indices generally reveals a strengthened co-movement relationship with the new group and a weakened link with the original group, regardless of a bull or bear market. The result is consistent with Boyer's (2011) label argument on co-movement. However, a subtler perspective reveals a rather insignificant change in the co-movement relationship for stock returns as components move from the Taiwan 50 to the Taiwan 100 index.
\end{abstract}

JEL: G12

KEYWORDS: Co-Movement, Label Effect, Exchange-Traded Funds

\section{INTRODUCTION}

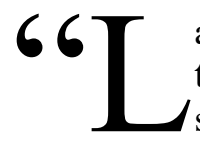

abel Co-movement" represents assets having the same label, which results in them moving in the same direction in terms of returns or turnover. In other words, when assets have the same style and are classified to be the same label, we can expect their returns to change in line with similar trends. Therefore, according to Boyer's (2011) argument, labels induce excess covariation in returns through the trading activity of investors, who allocate capital across styles delineated by these labels. Many theoretical and empirical studies examine the co-movement phenomenon in financial markets. According to conventional finance theory, the fundamentals of securities or the market's macroeconomics primarily cause this co-movement. However, according to the efficient market hypothesis, the price of a financial asset reflects all publicly available or hidden "insider" information relevant to its value without human behavioral influence, such as optimistic or pessimistic sentiment. Further, the excess returns of the capital asset pricing model (CAPM) reflects stocks' systematic risk, which also indicates both strong or weak correlations between securities and the market. However, several studies on behavioral finance find that the fundamentals do not completely explain the co-movement phenomenon (For example, the Siamese Twins co-movement noted by Froot and Dabora (1999); research by Barberis, Shleifer, and Wurgler (2005) and Boyer (2011); Claessens and Yafeh's (2012) finding of index co-movement; Pirinsky and Wang's (2006) study on regional HQ comovement; Muslu, Rebello, and Xu's (2014) study on recommendation comovement by sell-side analysis; Kumar and Lee's (2006) co-movement study of individual shareholders' 
sentiment; and Kumar, Page, and Spalt's (2016) research on co-movement and gambling motives). Jin and Myers (2006) argue that co-movement that is not driven by fundamentals could indicate a company's lack of specific information.

Barberis, Shleifer and Wurgler (2005) argue that volatility in investor sentiment based on specific habitats or categories could lead to non-fundamental co-movement. Kumar, Page, and Spalt (2016) study trading with the intent to gamble, with a focus on lottery-type stocks, and reveal returns co-movement within this stock category. Alternatively, Brockman, Liebenberg, and Schutte (2010) and Veldkamp (2006) find that information plays an important role in co-movement. Muslu, Rebello, and Xu (2014) reveal evidence implying that stock co-movement occurred during analysts' forecast of earnings announcements. Höchstötter, Meyer, Riordan, and Storkenmaier (2014) also discover that news could lead to stock comovement. However, Kumar and Lee (2006) demonstrate that high-ratio individuals' trading and sentiments could explain returns co-movements. However, neither macroeconomic news nor analysts' earnings forecast revisions can explain such a phenomenon.

Barberis and Shleifer (2003) propose their labeling argument to explain non-fundamental co-movement, stating that for the sake of simplicity, investors first categorize stocks in terms of their styles and then label them. Investors then allocate their assets among different labels, after which the co-movement phenomenon can occur (Labeling can simplify investment, as the investor will only need to reallocate assets among some specified labels, which differs from style investing). Boyer (2011) finds that an economically insignificant stock index could lead to co-movement in returns beyond its fundamentals. When a value stock is included in a growth index, the stock return co-moves with the new growth index; however, it has less of a comovement relationship with the original category. The opposite occurs when a growth stock becomes a value stock, in which the co-movement of the value index and return increases, and the correlation with growth stocks decreases. Boyer (2011) confirms that this result could explain the labeling theory. Claessens and Yafeh (2012) examine data from 40 developed and developing countries' stock that is newly included in the primary index, and find co-movement between the stock price and primary index, especially in those stocks with a low systematic risk $(\beta)$.

Behavioral finance studies generally conclude that systematic psychological bias could significantly affect pricing (Kahneman and Tversky, 1979, Armstrong and Fildes, 1984, Becker and Kuhn, 1984). The label phenomenon is a psychological bias involving a representativeness heuristic, implying that the use of experience serves as a reference for thinking, evaluating, and decision-making, to save time and improve efficiency. Boussaidi (2013), Luo (2013), and Liu and Du (2016) study the representativeness heuristic; the label effect is also a representativeness heuristic in that investors will make decisions using specific experiences in uncertain situations. For example, a company's past success could serve as its "representativeness" to lead investors' experience of good performance in the future. Reinforced by the representativeness heuristic concept, investors tend to overreact to a company's continuous outstanding profit.

An exchange-traded fund (ETF) is a fund that passively tracks the performance of a benchmark index with a specific style. An ETF's component stock is not actively decided by the fund manager, but passively determined by tracking the underlying index. Once the underlying index includes or excludes a proportion of the constituent stocks, the ETF should also follow by adjusting the proportion of its portfolio. Essentially, investors allocate their assets in ETF by tracking the performance of the index's style. We label those ETFs according to various styles. Therefore, by the various labels of ETF's returns and turnover, we can trace how the indices of those ETFs perform. Our study of label co-movement involves tracing how the indices of various labeled ETFs perform. We use the reorganization of component stocks to investigate changes in their ETF indices before and after the co-movement relationships with the original and new groups. The Taiwan 50 (TWN50) and Taiwan 100 (TM100) indices are types of ETFs that are excluded from the TWN50 and included in the TM100, or vice versa. The TWN50 includes a combination of stocks of 50 
listed companies with the greatest market capitalization and highest stability. The TM100 further includes the 51st to the 150th component stocks. Investors may consequently label companies differently for the TWN50 and TM100, resulting in a label switch in returns or turnover co-movement relationships with the same group's ETF index.

Prior studies generally investigate the co-movement phenomenon of individual stocks included or excluded in the primary index. They rarely focus on the co-movement phenomenon switch with ETF. However, we investigate the reorganized component ETF stock, and thus provide new evidence regarding label comovement. Stock liquidity and stability increases when the component stock is included in the TWN50 and excluded from the TM100, and alternatively, decreases when the component stock is excluded from the TWN50 and included in the TM100. Component reorganization also implies a label switch, from a good label to a poor label, and vice versa. Our study's economic implications of label co-movement differ slightly from those of Boyer's (2011); unlike us, the author has not addressed co-movement relationships with turnover. This study also emphasizes market sentiment to determine any variations in changes to comovement relationships in stock returns and turnover under different market sentiments (overly optimistic, optimistic, pessimistic, and overly pessimistic) and status (bull or bear market).

Our results indicate that component stocks switch from the TM100 to TWN50 indices and vice versa. However, except during the overly pessimistic period, including whole samples, market status (bull or bear market), and pessimistic market sentiment, will have increased co-movement relationships in stock returns and turnovers with the new group, and decreased links with the original group. This is broadly consistent with Boyer's (2011) labeling theory. However, the switch in a component stock from the TWN50 to the TM100 index indicates an insignificant co-movement relationship. It also indicates that investors would recognize significant differences when component stocks switch to a better label category, weakening the co-movement relationship with the original group and strengthening the new tie. Conversely, the opposite switch would have no profound impact on recognition because the co-movement relationship exhibits no apparent change.

This paper has five sections. The first section consists of the introduction. The second section includes a literature review discussing various references to the label effect and co-movement phenomenon. The third section describes the research method, hypothesis, research design model, sample, and operationally defines the research variables. The fourth section provides an empirical analysis, and the final section concludes and offers recommendations.

\section{LITERATURE REVIEW}

Barberis and Shleifer's (2003) theoretical model first proposed the label effect. When an investor prefers a specifically labeled stock, stock co-movement in the same style increases, and the relationship with the new category strengthens. They infer that the label switch leads to a higher co-movement relationship with the new label group. This study explores the label effect of a strengthening or weakening co-movement relationship in the returns and turnover during the switching of an ETF component stock, as stock return co-movement indicates significant covariance between the individual component stock and its corresponding index. Early literature, such as that of Vijh (1994), discovers a significant increase in the $\beta$ in evaluating the covariant relationships of individual and market returns for a component stock included in the S\&P 500 index. Wurgler and Zhuravskaya (2002) note similar results regarding the increase in comovement for component stocks included in the S\&P 500 index.

Many studies explore the co-movement relationships between component stock and index in returns when the component stock is included in the index, including those of Harris and Gurel (1986), Shleifer (1986), Lynch and Mendenhall (1997), Kaul, Mehrotra, and Morck (2000), Greenwood and Sosner (2007), and 
Greenwood (2005). They find that the $\beta$ and R2 (coefficients of determination) of both the component stock and index increase with inclusion and decrease with exclusion.

Barberis, Shleifer, and Wurgler (2005) use Vijh's (1994) research exploring the co-movement phenomenon for component stock returns on the S\&P 500 index from both the conventional and psychological perspectives. The former refers to co-movement resulting from the spread of fundamentals, while the latter emphasizes co-movement owing to investor sentiment. In addition, they divide the psychological perspective into three views: category, habitat, and information diffusion. Barberis and Shleifer (2003) propose the category view, which refers to the simplified investment strategy wherein investors prefer to allocate their assets according to specifically labeled stock categories such as small-cap, value stocks, and so on. The labeling factor in investors' decision-making processes could affect a category's stock price. Essentially, when investors move their investment from one category to another, category stocks with the same label convey the returns' co-movement, regardless of the stock's fundamentals. Barberis, Shleifer, and Wurgler (2005) argue that as a component stock is included in the S\&P 500 index, its $\beta$ increases and develops a co-movement relationship with the S\&P 500 index, which its fundamentals cannot explain.

Boyer (2011) studies component stocks on the S\&P/Barra index and uses the book-to-market (BM) ratio to differentiate them as value and growth stocks, and reclassifies stock labels according to changes in their BM ratios. Boyer's research reveals a significant co-movement relationship among stocks of the same style. Further, this switch from the original to new style results in a strong co-movement in stock returns and turnover with the new style group, as well as a weaker link with the original. The S\&P/Barra index could serve as an important indicator for category stock, either "value" or "growth," among which investors allocate their assets. Therefore, Boyer (2011) argues that style investment generally implies investors' psychological bias, causing significant co-movement in category stocks with the same BM value.

We explore the label co-movement of reorganized component stocks in the ETF. This differs from Boyer's (2011) work, which focuses on style label changes for value and growth stocks. We also investigate the perceptions of component stocks with different labeling. The TWN50 represents the best 50 component stocks with liquidity and stability, followed by the TM100. The inclusion of component stock in the TWN50 from the TM100 implies an upgrade in its image, and vice versa for a downgrade. Additionally, prior studies do not discuss turnover co-movement or label changes in accordance with market status, which our research includes. Our study categorizes the sentiment for market status as overly optimistic, optimistic, pessimistic, and overly pessimistic, to observe the differences not only in this relationship, but also in the bull or bear market classification.

\section{DATA AND METHODOLOGY}

\section{$\underline{\text { Data }}$}

Based on Barberis and Shleifer's (2003) labeling theory, as well as Barberis, Shleifer, and Wurgler's (2005) and Boyer's (2011) empirical analyses of index component stock co-movement, we hypothesize that the co-movement phenomenon will also occur during the reorganization of component stocks in the TWN50 and TM100 indices. Therefore, we utilize data for component stocks in the TWN50 and TM100 indices as the research sample. The sample period is from January 1, 2006, to May 31, 2015, and contains about 2,332 daily observations.

The TWN50 is an ETF with components that include a combination of stocks from the 50 listed companies with the greatest market capitalization and the highest stability in Taiwan's stock market. Similarly, the TM100 includes the $51^{\text {st }}$ to the $150^{\text {th }}$ component stocks. We use component stocks that move between the TM100 and TWN50, and vice versa, as our sample. We assume that before the switch from the original group, the co-movement relationship would significantly decrease between the stock returns or turnover 
and the original ETF index (hereafter the "original" and "new" groups, respectively). Moreover, after the switch to the new group, the co-movement relationship would significantly increase between stock returns or turnover and the new ETF index. This data is sourced from the Taiwan Economic Journal (TEJ).

We base our analysis on Barberis and Shleifer (2003) and Boyer's (2011) theory of label co-movement. The TWN50 ETF in Taiwan provides investors with a benchmark for large-cap companies. This index measures the performance of large-cap companies, reflecting the distinctive top-50 firms by market capitalization. The components of the TWN50 generally have greater market capitalization, higher liquidity, and stable returns characteristics in this market segment. The TM100 is a mid-cap index of ETFs, with medium-sized market capitalization, relatively unstable returns, and lower liquidity.

A label switch indicates that a component stock is included in the ETF and excluded from another ETF. The study excludes 27 component stocks from the TM100 and includes them in the TWN50, while 28 component stocks switched in the opposite direction.

\section{$\underline{\text { Variable Definition }}$}

We calculate the returns and turnover of the component stocks on the TWN50 and TM100 weighted on market capitalization to test for any change in the weighted returns and turnover co-movement relationship of the component stock in the original or new group, before and after the adjustment.

To observe the changes in co-movement relationships, we further divide the research market status into bull and bear periods, and market sentiments into optimistic, overly optimistic, pessimistic, and overly pessimistic in accordance with the TAIEX options volatility index. According to Fabozzi and Francis' (1979) market status classification, the TAIEX options volatility index increasing over a three-month period serves as an indication of a bull market; conversely, a decrease over a three-month period indicates a bear market. According to the TAIEX options volatility index, market sentiment is classified with the values of under $15,15-20,21-40$, and over 40 as thresholds for the 4 sentiments: overly optimistic, optimistic, pessimistic, and overly pessimistic (Chen and Zhou, 2014).

Established in 1997, the TAIEX options volatility index applies the volatility index (VIX) methodology from the Chicago Board Options Exchange (CBOE) to trading activity in Taiwan's options market. This accurately reflects the market's current price volatility, which provides options traders with more information to help them evaluate market conditions and make appropriate trading decisions. The VIX utilizes S\&P 100 index options prices to generate and imply volatility. This reflects the market's expectations of future market volatility to provide options traders with more information to plan their trading and hedging strategies, and offer a more practical and balanced perspective on the market's outlook. Generally, while a higher VIX indicates that traders expect greater volatility in the equities market, a lower VIX indicates that they expect lower volatility in the equities market. Serving as a reflection of the change in investor sentiment, the index has long been known as the "investor fear gauge."

\section{Test of ETF Component Stock Returns' Co-Movement}

This study adopts Boyer's (2011) method to test the average coefficients' change in Equation (1). We regress the component stock on the ETF index for the returns' co-movements phenomenon before or after the event date of inclusion and exclusion from the TWN50 and TM100.

$r_{i t}=\beta_{i o}+\beta_{i w} r_{w t}+\beta_{i m} r_{m t}+e_{i t}$

In Equation (1),

$r_{i t}$ : Daily log returns of the reorganized component stock 
$r_{w r}:$ Weighted daily log returns of the TWN50 index

$r_{m t}$ : Weighted daily log returns of the TM100 index

The event date is the day of exclusion and inclusion of the component stocks, either as the switch from the TM100 to the TWN50 or vice versa. We use Equation (1) to regress the individual component stocks on the ETF index for the returns' co-movement phenomenon before and after one-month to six-months to the event day. Further, we test for the statistical significance of $\beta$ 's average change before and after one month to six months to the event date using equations $(2 a)$ and $(2 b)$ as follows:

$$
\begin{aligned}
\Delta \bar{\beta}_{w} & =\sum_{i=1}^{n} \frac{\beta_{i w}^{p s t}-\beta_{i w}^{p r e}}{n} \\
\Delta \bar{\beta}_{m} & =\sum_{i=1}^{n} \frac{\beta_{i m}^{p s t}-\beta_{i m}^{p r e}}{n}
\end{aligned}
$$

In Equations (2a) and (2b),

$\beta^{\text {pre }}, \beta^{\text {pst }}$ : The estimate of regression before and after the event date, respectively.

$n$ : The number of reorganized component stocks.

$w, m$ : The regressions of component stocks on the TWN50 and TM100, respectively.

According to Boyer's (2011) label co-movement theory, for the component stocks switching from TM100 to TWN50, we expect the degree of co-movement of the TWN50's returns to increase with a positive $\Delta \bar{\beta}_{w}$. Conversely, we expect the degree of co-movement of the TM100's returns to decrease with a negative $\Delta \bar{\beta}_{m}$. The null and alternative hypotheses for this test are as follows:

$\left\{\begin{array}{c}H_{0}: \Delta \bar{\beta}_{w} \leq 0 \\ H_{1}: \Delta \bar{\beta}_{w}>0\end{array} \quad\left\{\begin{array}{c}H_{0}: \Delta \bar{\beta}_{m} \geq 0 \\ H_{1}: \Delta \bar{\beta}_{m}<0\end{array}\right.\right.$

In contrast, when a component stock switches from the TWN50 to the TM100, we expect a negative $\Delta \bar{\beta}_{w}$ and a positive $\Delta \bar{\beta}_{m}$, respectively; the null and alternative hypothesis are as follows:

$\left\{\begin{array}{c}H_{0}: \Delta \bar{\beta}_{w} \geq 0 \\ H_{1}: \Delta \bar{\beta}_{w}<0\end{array} \quad\left\{\begin{array}{c}H_{0}: \Delta \bar{\beta}_{m} \leq 0 \\ H_{1}: \Delta \bar{\beta}_{m}>0\end{array}\right.\right.$

\section{Test of ETF Component Stock Turnovers' Co-Movement}

This study uses the average coefficients' change in Equation (4) to indicate the regression of the component stock on the ETF index for the turnovers' co-movement phenomenon before and after the event date of inclusion and exclusion from the TWN50 and the TM100.

$\tau_{i t}=\theta_{i o}+\theta_{i w} \tau_{w t}+\theta_{i m} \tau_{m t}+e_{i t}$

In Equation (4),

$\tau_{i t}$ : Daily turnover of the reorganized component stock

$\tau_{w t}$ : Daily turnover of the TWN50 index 
$\tau_{m t}:$ Daily turnover of the TM100 index

We exclude component stocks from the TM100 and include them in the TWN50, or exclude them from the TWN50 and include them in the TM100. We then regress the individual component stocks on the ETF index for the turnovers' co-movement phenomenon before and after one-month to six-months to the event day in Equation (4). Further, we test for the statistical significance of $\beta$ 's average change before and after one-month to six-months to the event date, using equations (5a) and (5b).

$$
\begin{aligned}
\Delta \bar{\theta}_{w} & =\sum_{i=1}^{n} \frac{\theta_{i w}^{p s t}-\theta_{i w}^{p r e}}{n} \\
\Delta \bar{\theta}_{m} & =\sum_{i=1}^{n} \frac{\theta_{i m}^{p s t}-\theta_{i m}^{p r e}}{n}
\end{aligned}
$$

In Equations (5a) and (5b),

$\beta^{\text {pre }}, \beta^{p s t}:$ The estimate of regression before and after the event date, respectively.

$n$ : The number of reorganized component stocks.

$\mathrm{w}, \mathrm{m}$ : The regressions of component stocks on the TWN50 and TM100, respectively.

Based on the label co-movement theory, for a switch of a component stock from the TM100 to the TWN50, we expect that $\Delta \bar{\theta}_{w}$ is positive and $\Delta \bar{\theta}_{m}$ is negative. The null and alternative hypotheses are:

$\left\{\begin{array}{c}H_{0}: \Delta \bar{\theta}_{w} \leq 0 \\ H_{1}: \Delta \bar{\theta}_{w}>0\end{array} \quad\left\{\begin{array}{l}H_{0}: \Delta \bar{\theta}_{m} \geq 0 \\ H_{1}: \Delta \bar{\theta}_{m}<0\end{array}\right.\right.$

In contrast, for the component stocks in the TM100 and not in the TWN50, we expect $\Delta \bar{\theta}_{w}$ to be negative and $\Delta \bar{\theta}_{m}$ to be positive. The null and alternative hypotheses are:

$\left\{\begin{array}{c}H_{0}: \Delta \bar{\theta}_{w} \geq 0 \\ H_{1}: \Delta \bar{\theta}_{w}<0\end{array} \quad\left\{\begin{array}{c}H_{0}: \Delta \bar{\theta}_{m} \leq 0 \\ H_{1}: \Delta \bar{\theta}_{m}>0\end{array}\right.\right.$

\section{EMPIRICAL RESULTS}

\section{Co-Movement Test of the Full Sample}

Table 1 reports the test results of the method described in Section 3. The analysis of reorganized component stocks from the TM100 to the TWN50, as noted in Panel A of Table 1, regardless of returns or turnover, has a significantly weakened co-movement relationship with the original group (both $\Delta \bar{\beta}_{m}$ and $\Delta \bar{\theta}_{m}$ are significantly negative) and a significantly strengthened co-movement relationship with the new group (both $\Delta \bar{\beta}_{w}$ and $\Delta \bar{\theta}_{w}$ are significantly positive) throughout the one-month to six-month period. However, our analysis in Panel B of Table 1 for component stocks reorganized from the TWN50 to the TM100 indicates a weakened co-movement relationship between returns and the original group $\left(\Delta \bar{\beta}_{w}\right.$ is negative) and a strengthened link with the new group $\left(\Delta \bar{\beta}_{m}\right.$ is positive), which is significant only during the sixmonth period. Regarding turnover, the co-movement relationship with the original group weakened $\left(\Delta \bar{\theta}_{w}\right.$ is negative and significant) and strengthened with the new group $\left(\Delta \bar{\theta}_{m}\right.$ is positive and significant). 
Table 1: Co-Movement Test of the Full Sample

\begin{tabular}{|c|c|c|c|c|c|}
\hline \multicolumn{5}{|c|}{ Panel A: The Component Stocks Excluded from the TM100 and Included in the TWN50 } & $=27$ \\
\hline TWN50 & $\Delta \overline{\boldsymbol{\beta}}_{w}$ & t-statistic & TWN50 & $\Delta \overline{\boldsymbol{\theta}}_{w}$ & t-statistic \\
\hline $\mathrm{r} 1$ & 0.5578 & $2.0605^{* *}$ & $\tau 1$ & 0.2250 & 0.4508 \\
\hline $\mathrm{r} 2$ & 0.5822 & $2.9337^{* * *}$ & $\tau 2$ & 0.9178 & $2.6698^{* * *}$ \\
\hline r3 & 0.4501 & $2.6310^{* * *}$ & $\tau 3$ & 0.8057 & $3.1883^{* * *}$ \\
\hline $\mathrm{r} 4$ & 0.3682 & $2.4660^{* *}$ & $\tau 4$ & 0.8619 & $3.0426^{* * *}$ \\
\hline $\mathrm{r} 5$ & 0.4272 & $3.2182^{* * *}$ & $\tau 5$ & 1.3252 & $4.0147^{* * *}$ \\
\hline r6 & 0.4937 & $3.6363^{* * *}$ & $\tau 6$ & 1.3456 & $4.0212^{* * *}$ \\
\hline TM100 & $\Delta \overline{\boldsymbol{\beta}}_{m}$ & t-statistic & TM100 & $\Delta \overline{\boldsymbol{\theta}}_{m}$ & t-statistic \\
\hline $\mathrm{r} 1$ & -0.5848 & $-2.1791^{* *}$ & $\tau 1$ & -0.2385 & -0.8062 \\
\hline $\mathrm{r} 2$ & -0.4878 & $-2.2019^{* *}$ & $\tau 2$ & -0.6104 & $-3.1666^{* * *}$ \\
\hline r3 & -0.3660 & $-2.0185^{* *}$ & $\tau 3$ & -0.6626 & $-2.9698^{* * *}$ \\
\hline $\mathrm{r} 4$ & -0.3573 & $-2.4003^{* *}$ & $\tau 4$ & -0.6780 & $-3.6545^{* * *}$ \\
\hline $\mathrm{r} 5$ & -0.4256 & $-3.0901^{* * *}$ & $\tau 5$ & -0.7170 & $-4.1506^{* * *}$ \\
\hline r6 & -0.4804 & $-3.4426^{* * *}$ & $\tau 6$ & -0.7942 & $-4.6035^{* * *}$ \\
\hline \multicolumn{5}{|c|}{ Panel B: The Component Stocks Excluded from the TWN50 and Included in the TM100 } & \\
\hline TWN50 & $\Delta \overline{\boldsymbol{\beta}}_{w}$ & t-statistic & TWN50 & $\Delta \bar{\theta}_{w}$ & t-statistic \\
\hline $\mathrm{r} 1$ & -0.1547 & -0.6431 & $\tau 1$ & -1.2905 & $-2.0494^{* *}$ \\
\hline $\mathrm{r} 2$ & -0.1047 & -0.6680 & $\tau 2$ & -1.7379 & $-2.7905^{* * *}$ \\
\hline r3 & -0.0669 & -0.5609 & $\tau 3$ & -1.3992 & $-2.7838^{* * *}$ \\
\hline $\mathrm{r} 4$ & -0.0691 & -0.6396 & $\tau 4$ & -1.5744 & $-2.3404^{* *}$ \\
\hline r5 & -0.0203 & -0.1991 & $\tau 5$ & -1.0375 & $-1.6860^{*}$ \\
\hline r6 & -0.1386 & $-1.5593^{*}$ & $\tau 6$ & -0.7346 & -1.1856 \\
\hline TM100 & $\Delta \overline{\boldsymbol{\beta}}_{m}$ & t-statistic & TM100 & $\Delta \overline{\boldsymbol{\theta}}_{\boldsymbol{m}}$ & t-statistic \\
\hline $\mathrm{r} 1$ & 0.2661 & 0.8309 & $\tau 1$ & 0.8238 & $2.1066^{* *}$ \\
\hline $\mathrm{r} 2$ & 0.2081 & 1.0956 & $\tau 2$ & 1.0317 & $2.0749^{* *}$ \\
\hline r3 & 0.0951 & 0.6714 & $\tau 3$ & 1.1005 & $1.7705^{* *}$ \\
\hline r4 & 0.0884 & 0.6801 & $\tau 4$ & 1.2568 & $1.5253^{*}$ \\
\hline $\mathrm{r} 5$ & 0.0588 & 0.5450 & $\tau 5$ & 1.0477 & 1.3039 \\
\hline r6 & 0.1794 & $1.9773^{* *}$ & $\tau 6$ & 0.9250 & 1.2189 \\
\hline
\end{tabular}

Panels $A$ and B represent analytical tests on the average changes in the co-movement of weighted stock returns and turnover, respectively, for those component stocks excluded from the TWN50 and included in the TM100, or excluded from the TWN50 and included in the TM100 before and after their label changes, from one-month to six-month periods. $\Delta \bar{\beta}_{w}$ and $\Delta \bar{\beta}_{m}$ represent the average change in the co-movement of weighted returns, and $\Delta \bar{\theta}_{w}$ and $\Delta \bar{\theta}_{m}$ represent the average changes in the weighted turnover's co-movement. Subscripts $\mathrm{w}$ and $\mathrm{m}$ respectively represent the TWN50 and TM100. Further, $r 1$ represents the test period for weighted stock returns one month before and after the style change; $\tau 1$ represents the test period for weighted stock turnovers one month before and after the style change. Thus, the test period spans one month to six months. ***, **, and * indicate significance at the $1 \%, 5 \%$, and $10 \%$ levels, respectively.

The results of Table 1 differ slightly from Boyer's (2011) research, from an economic perspective. The TWN50 represents the 50 listed companies with the greatest market capitalization and the highest stability, while the TM100 represents mid-cap stocks with higher degrees of return volatility. Component stocks excluded from the TWN50 but included in the TM100 imply a "downgrade," and component stocks excluded from the TM100 and included in the TWN50 imply an "upgrade." Apart from finding an upgraded turnover, we also find that downgraded component stocks have a significantly weakened co-movement with the original group and strengthened co-movement with the new group. However, only the stock returns of the "upgraded" component show the same phenomenon with a significantly weakened co-movement with the original group and strengthened co-movement with the new group. With regard to the comovement phenomenon, we find that investors do not fully recognize the component stock label downgrade, and thus, the stock returns' co-movement does not indicate a significant change. 


\section{Co-Movement Testing in Bull and Bear Markets}

Table 1 represents the test results for a full sample. We test any consistency in changes in co-movement relationships owing to market status (bull or bear) or market sentiment (optimism versus pessimism). To understand any differences during bull or bear markets in the co-movement relationships depicted in Table 1, we follow Fabozzi and Francis' (1979) standards to divide the research periods into either bull or bear markets. Table 2 reports the test results.

Table 2: Co-Movement Testing in the Bull Market

\begin{tabular}{|c|c|c|c|c|c|c|}
\hline \multicolumn{6}{|c|}{ Panel A: The Component Stocks Excluded from the TM100 and Included in the TWN50 in the Bull Market } & \multirow[t]{2}{*}{$\mathrm{n}=19$} \\
\hline TWN50 & $\Delta \overline{\boldsymbol{\beta}}_{w}$ & t-statistic & TWN50 & $\Delta \overline{\boldsymbol{\theta}}_{w}$ & t-statistic & \\
\hline $\mathrm{r} 1$ & 0.7050 & $2.3864^{* *}$ & $\tau 1$ & -0.3752 & -1.1615 & \\
\hline r2 & 0.6858 & $2.8510^{* * *}$ & $\tau 2$ & 0.6227 & $1.8801^{* *}$ & \\
\hline r3 & 0.5833 & $2.9889^{* * *}$ & $\tau 3$ & 0.7506 & $2.9861^{* * *}$ & \\
\hline r4 & 0.4919 & $2.8168^{* * *}$ & $\tau 4$ & 0.6729 & $2.3686^{* *}$ & \\
\hline r5 & 0.5904 & $3.6968^{* * *}$ & $\tau 5$ & 0.9510 & $2.8291^{* * *}$ & \\
\hline r6 & 0.7082 & $4.7949^{* * *}$ & $\tau 6$ & 1.0430 & $3.3125^{* * *}$ & \\
\hline TM100 & $\Delta \overline{\boldsymbol{\beta}}_{m}$ & t-statistic & TM100 & $\Delta \overline{\boldsymbol{\theta}}_{m}$ & t-statistic & \\
\hline r1 & -0.5688 & $-1.9610^{* *}$ & $\tau 1$ & 0.0743 & 0.2853 & \\
\hline r2 & -0.4309 & $-1.5874^{*}$ & $\tau 2$ & -0.3780 & $-1.9263^{* *}$ & \\
\hline r3 & -0.3784 & $-1.6942^{*}$ & $\tau 3$ & -0.5335 & $-2.0365^{* *}$ & \\
\hline r4 & -0.4257 & $-2.3941^{* *}$ & $\tau 4$ & -0.4830 & $-2.1951^{* *}$ & \\
\hline r5 & -0.5319 & $-3.1635^{* * *}$ & $\tau 5$ & -0.4117 & $-2.2818^{* *}$ & \\
\hline r6 & -0.6202 & $-3.6550^{* * *}$ & $\tau 6$ & -0.4484 & $-2.8634^{* * *}$ & \\
\hline \multicolumn{6}{|c|}{ Panel B: The Component Stocks Excluded from the TWN50 and Included in the TM100 in the Bull Market } & $\mathrm{n}=19$ \\
\hline TWN50 & $\Delta \overline{\boldsymbol{\beta}}_{w}$ & t-statistic & TWN50 & $\Delta \overline{\boldsymbol{\theta}}_{w}$ & t-statistic & \\
\hline r1 & 0.2842 & 1.1962 & $\tau 1$ & -2.3901 & $-3.9613^{* * *}$ & \\
\hline r2 & -0.0444 & -0.2380 & $\tau 2$ & -2.2304 & $-2.6785^{* * *}$ & \\
\hline r3 & -0.0021 & -0.0147 & $\tau 3$ & -1.8291 & $-2.7006^{* * *}$ & \\
\hline $\mathrm{r} 4$ & 0.0122 & 0.0890 & $\tau 4$ & -1.9071 & $-1.9512^{* *}$ & \\
\hline r5 & 0.0332 & 0.2430 & $\tau 5$ & -1.5033 & $-1.7040^{*}$ & \\
\hline r6 & -0.1190 & -1.0582 & $\tau 6$ & -1.2652 & $-1.4387^{*}$ & \\
\hline TM100 & $\Delta \overline{\boldsymbol{\beta}}_{m}$ & t-statistic & TM100 & $\Delta \overline{\boldsymbol{\theta}}_{m}$ & t-statistic & \\
\hline $\mathrm{r} 1$ & -0.0934 & -0.2443 & $\tau 1$ & 1.1485 & $2.0463^{* *}$ & \\
\hline r2 & 0.1481 & 0.6211 & $\tau 2$ & 1.1867 & $1.6476^{*}$ & \\
\hline r3 & 0.0048 & 0.0284 & $\tau 3$ & 1.2869 & $1.4207^{*}$ & \\
\hline $\mathrm{r} 4$ & -0.0351 & -0.2093 & $\tau 4$ & 1.4572 & 1.2063 & \\
\hline r5 & -0.0265 & -0.1833 & $\tau 5$ & 1.4313 & 1.2160 & \\
\hline r6 & 0.1372 & 1.1904 & $\tau 6$ & 1.2823 & 1.1544 & \\
\hline
\end{tabular}

Panels $A$ and $B$ represent analytical tests on the average changes in the co-movement of weighted stock returns and turnover, respectively, for those component stocks excluded from the TWN50 and included in the TM100, or excluded from the TWN50 and included in the TM100 before and after their label changes, from one-month to six-month periods. $\Delta \bar{\beta}_{w}$ and $\Delta \bar{\beta}_{m}$ represent the average change in the co-movement of weighted returns, and $\Delta \bar{\theta}_{w}$ and $\Delta \bar{\theta}_{m}$ represent the average changes in the weighted turnover's co-movement. Subscripts $\mathrm{w}$ and $\mathrm{m}$ respectively represent the TWN50 and TM100. Further, rl represents the test period for weighted stock returns one month before and after the style change; $\tau 1$ represents the test period for weighted stock turnovers one month before and after the style change. Thus, the test period spans one month to six months. ***, **, and * indicate significance at the $1 \%, 5 \%$, and $10 \%$ levels, respectively.

Panel A in Table 2 suggests that during a bull market period, the significance of a label switch in the comovement relationship, is similar to that in Table 1. Further, component stocks included in the TWN50 and excluded from the TM100, regardless of returns or turnover, indicate a significantly weakened comovement relationship with the original group and a significantly strengthened tie with the new group. With regard to returns, our study indicates an insignificant negative relationship in the switch of the comovement relationship with the original groups of component stocks excluded from the TWN50 and included in the TM100, and an insignificant positive co-movement relationship with the new groups. Moreover, regarding turnover, as in Table 1, the results indicate a significantly decreasing co-movement relationship with the original group and a significantly increasing relationship with the new group. This occurs only in the difference test between one and two months. 
Table 3 reveals that during bear market periods, when a component stock is included in the TWN50 and excluded from the TM100, its turnover's co-movement relationship indicates a similar direction and significance as in the bull market. The relationship with the new group strengthens, but weakens with the original group. For the returns of component stocks, the test of the switch in the co-movement relationship is insignificant, although the sign is approximately the same. Alternatively, for component stocks in the TM100 but not in the TWN50, the results for the stock returns' co-movement relationship with the original group reveal a significant weakening for some specified months, while the total months of the turnover switches weakening the co-movement relationship decrease significantly. The switch months in the stock returns' co-movement relationship with the new group increase significantly and turnovers' co-movement relationship changes insignificantly.

Table 3: Co-Movement Testing in the Bear Market

\begin{tabular}{|c|c|c|c|c|c|c|}
\hline \multicolumn{6}{|c|}{ Panel A: The Component Stocks Excluded from the TM100 and Included in the TWN50 in the Bear Market } & \multirow[t]{2}{*}{$\mathrm{n}=8$} \\
\hline TWN50 & $\Delta \overline{\boldsymbol{\beta}}_{w}$ & t-statistic & TWN50 & $\Delta \overline{\boldsymbol{\theta}}_{w}$ & t-statistic & \\
\hline r1 & 0.2081 & 0.3464 & $\tau 1$ & 1.6505 & 1.1461 & \\
\hline $\mathrm{r} 2$ & 0.3362 & 0.9396 & $\tau 2$ & 1.6187 & $1.9185^{* *}$ & \\
\hline r3 & 0.1339 & 0.3965 & $\tau 3$ & 0.9367 & $1.4607^{*}$ & \\
\hline r4 & 0.0743 & 0.2701 & $\tau 4$ & 1.3106 & $1.9075^{* *}$ & \\
\hline r5 & 0.0396 & 0.2129 & $\tau 5$ & 2.2138 & $3.0837^{* * *}$ & \\
\hline r6 & -0.0158 & -0.0743 & $\tau 6$ & 2.0643 & $2.4791^{* *}$ & \\
\hline TM100 & $\Delta \overline{\boldsymbol{\beta}}_{m}$ & t-statistic & TM100 & $\Delta \overline{\boldsymbol{\theta}}_{m}$ & t-statistic & \\
\hline r1 & -0.6227 & -0.9988 & $\tau 1$ & -0.9814 & -1.2990 & \\
\hline $\mathrm{r} 2$ & -0.6232 & $-1.5497^{*}$ & $\tau 2$ & -1.1621 & $-2.8293^{* *}$ & \\
\hline r3 & -0.3365 & -1.0274 & $\tau 3$ & -0.9693 & $-2.2483^{* *}$ & \\
\hline $\mathrm{r} 4$ & -0.1948 & -0.6917 & $\tau 4$ & -1.1413 & $-3.7568^{* * *}$ & \\
\hline r5 & -0.1731 & -0.7576 & $\tau 5$ & -1.4423 & $-5.5079^{* * *}$ & \\
\hline r6 & -0.1484 & -0.6928 & $\tau 6$ & -1.6155 & $-5.4958^{* * *}$ & \\
\hline \multicolumn{6}{|c|}{ Panel B: The Component Stocks Excluded from the TWN50 and Included in the TM100 in the Bear Market } & $\mathrm{n}=9$ \\
\hline TWN50 & $\Delta \overline{\boldsymbol{\beta}}_{w}$ & t-statistic & TWN50 & $\Delta \overline{\boldsymbol{\theta}}_{w}$ & t-statistic & \\
\hline $\mathrm{r} 1$ & -1.0812 & $-2.5408^{* *}$ & $\tau 1$ & 1.0311 & 0.8589 & \\
\hline $\mathrm{r} 2$ & -0.2319 & -0.7753 & $\tau 2$ & -0.6982 & -0.9169 & \\
\hline r3 & -0.2036 & -0.9141 & $\tau 3$ & -0.4915 & -0.8665 & \\
\hline $\mathrm{r} 4$ & -0.2409 & $-1.4478^{*}$ & $\tau 4$ & -0.8719 & $-2.4902^{* *}$ & \\
\hline $\mathrm{r} 5$ & -0.1331 & -1.0002 & $\tau 5$ & -0.0542 & -0.1708 & \\
\hline r6 & -0.1799 & -1.1982 & $\tau 6$ & 0.3856 & 1.0870 & \\
\hline TM100 & $\Delta \overline{\boldsymbol{\beta}}_{m}$ & t-statistic & TM100 & $\Delta \overline{\boldsymbol{\theta}}_{m}$ & t-statistic & \\
\hline r1 & 1.0249 & $1.9491^{* *}$ & $\tau 1$ & 0.1383 & 0.9159 & \\
\hline $\mathrm{r} 2$ & 0.3349 & 1.0293 & $\tau 2$ & 0.7043 & $2.1070^{* *}$ & \\
\hline r3 & 0.2859 & 1.0793 & $\tau 3$ & 0.7068 & $1.9574^{* *}$ & \\
\hline $\mathrm{r} 4$ & 0.3490 & $1.9673^{* *}$ & $\tau 4$ & 0.8339 & $2.0578^{* *}$ & \\
\hline r5 & 0.2388 & $1.8481^{*}$ & $\tau 5$ & 0.2378 & 0.8508 & \\
\hline r6 & 0.2685 & $1.8146^{*}$ & $\tau 6$ & 0.1707 & 0.5972 & \\
\hline
\end{tabular}

Panels $A$ and B represent analytical tests on the average changes in the co-movement of weighted stock returns and turnover, respectively, for those component stocks excluded from the TWN50 and included in the TM100, or excluded from the TWN50 and included in the TM100 before and after their label changes, from one-month to six-month periods. $\Delta \bar{\beta}_{w}$ and $\Delta \bar{\beta}_{m}$ represent the average change in the co-movement of weighted returns, and $\Delta \bar{\theta}_{w}$ and $\Delta \bar{\theta}_{m}$ represent the average changes in the weighted turnover's co-movement. Subscripts $\mathrm{w}$ and $\mathrm{m}$ respectively represent the TWN50 and TM100. Further, rl represents the test period for weighted stock returns one month before and after the style change; $\tau 1$ represents the test period for weighted stock turnovers one month before and after the style change. Thus, the test period spans one month to six months. ***, **, and * indicate significance at the $1 \%, 5 \%$, and $10 \%$ levels, respectively.

Compared to the bull market period test results in Table 2, Table 3 indicates that regardless of the component stock's reorganization direction, either from the TM100 to the TWN50 or from the TWN50 to 
the TM100, the turnovers in the switch co-movement relationship in the bear market are similar to those in the bull market. However, the returns in terms of the aspects of the co-movement relationship involving the new and original groups, as included in the TWN50 and excluded from the TM100, are significantly strengthened or weakened in the co-movement relationship during the bull market, while the bear market period is insignificant. Regarding the component stock returns' co-movement relationship for those included in the TM100 and excluded from the TWN50, it is insignificant in the bull market, regardless of whether the co-movement relationship strengthens or weakens, but is significant in the bear market. This result implies a slight difference between bull and bear market periods in the stock returns' co-movement relationship.

Compared with the TWN50, stocks in the TM100 index have poor liquidity and higher risk. The label switch for the component stock is excluded from the TM100 and included in the TWN50. The test results suggest the following. During the bull market period, investors strongly recognize any label switch from poor liquidity and high risk to high liquidity and low risk, which reveals a strengthened co-movement relationship with the new group and a weakened relationship with the original group. During the bear market period, investors weakly recognize this label switch; the results indicate an insignificant change in the co-movement relationships among the new and old groups. Alternatively, the label switch from exclusion from the TWN50 to inclusion in the TM100 implies a change in the component stock's characteristics from higher liquidity and lower risk to lower liquidity and higher risk. Investors weakly recognize this label switch during bull market periods and strongly recognize the label switch during bear market periods. However, the label switch test of stocks returns' co-movement relationship is significant during the bear market period.

We have the TWN50 and the TM100 to imply "good" and "poor" labels, respectively. We find that investors strongly recognize the switch from the "poor" to "good" label in bull markets. Thus, the comovement relationship weakens with the original "poor" label and significantly strengthens with the new "good" label. However, it is weakly insignificant during bear markets. In contrast, investors recognize the switch from "good" to "poor" weakly in bull markets, but strongly in bear markets. The co-movement relationship is insignificant in bull markets and significant in bear markets. Consequently, investors' cognition depends on either bull or bear markets and the label switch from "good" to "poor" or the opposite.

\section{Co-Movement Testing of Investor Sentiment}

The study of investor sentiment has recently gained popularity in behavioral finance. The volatility index, which is a gauge of investors' fear, has become an important hedging and speculating product in financial markets. Label co-movements may vary under different market sentiments. To investigate the differences, we utilize the TAIEX options volatility index and categorize the research into four periods: overly optimistic, optimistic, pessimistic, and overly pessimistic. Tables 4 to 7 report the co-movement test results for these periods.

The test results from Panel A in Table 4 note the co-movement of stocks returns and turnover during periods of overly optimistic sentiment. This is especially the case in the six-month period before and after the TWN50 index's inclusion and TM100 index's exclusion; the longer the period, the stronger the relationship with the TWN50 but the weaker the relationship with the TM100 in co-movements is. Compared to a bull market, it is more significant only in the switch before and after a shorter period. Compared to Table 2 for the test of the bull market, Table 4 Panel B shows a decrease in significance, and stock returns are similar to stock turnovers in the switch of the co-movement relationship during the overly optimistic sentiment period. Component stocks in the TM100 but not in the TWN50 demonstrated an insignificant co-movement relationship in stock returns with the new and original groups. 
Table 4: Co-Movement Testing in the Overly Optimistic Market

\begin{tabular}{|c|c|c|c|c|c|c|}
\hline \multicolumn{6}{|c|}{ Panel A: The Component Stocks Excluded from the TM100 and Included in the TWN50 in the Overly Optimistic Market } & \multirow[t]{2}{*}{$\mathrm{n}=7$} \\
\hline TWN50 & $\Delta \overline{\boldsymbol{\beta}}_{w}$ & t-statistic & TWN50 & $\Delta \overline{\boldsymbol{\theta}}_{\boldsymbol{w}}$ & t-statistic & \\
\hline $\mathrm{r} 1$ & 0.1312 & 0.2501 & $\tau 1$ & -0.2363 & -0.5105 & \\
\hline $\mathrm{r} 2$ & 0.1047 & 0.2802 & $\tau 2$ & 0.4526 & 0.8995 & \\
\hline r3 & 0.2191 & 0.7393 & $\tau 3$ & 0.8186 & $1.8559^{*}$ & \\
\hline r4 & 0.2777 & 1.2030 & $\tau 4$ & 0.7026 & $2.2047^{* *}$ & \\
\hline $\mathrm{r} 5$ & 0.4691 & $2.1196^{* *}$ & $\tau 5$ & 0.8891 & $1.9478^{* *}$ & \\
\hline r6 & 0.6316 & $2.2371^{* *}$ & $\tau 6$ & 1.1293 & $1.9965^{* *}$ & \\
\hline TM100 & $\Delta \overline{\boldsymbol{\beta}}_{m}$ & t-statistic & TM100 & $\Delta \overline{\boldsymbol{\theta}}_{m}$ & t-statistic & \\
\hline$\overline{\mathrm{r} 1}$ & -0.0962 & -0.1636 & $\tau 1$ & 0.0016 & 0.0027 & \\
\hline $\mathrm{r} 2$ & -0.1164 & -0.2041 & $\tau 2$ & -0.5929 & $-1.5592^{*}$ & \\
\hline r3 & -0.1080 & -0.2829 & $\tau 3$ & -0.9039 & $-1.7086^{*}$ & \\
\hline r4 & -0.2789 & -1.2573 & $\tau 4$ & -0.9736 & $-2.4396^{* *}$ & \\
\hline r5 & -0.4845 & $-2.1702^{* *}$ & $\tau 5$ & -0.5869 & $-1.6534^{*}$ & \\
\hline r6 & -0.6621 & $-2.0655^{* *}$ & $\tau 6$ & -0.5416 & $-1.5747^{*}$ & \\
\hline \multicolumn{6}{|c|}{ Panel B: The Component Stocks Excluded from the TWN50 and Included in the TM100 in the Overly Optimistic Market } & $\mathrm{n}=6$ \\
\hline TWN50 & $\Delta \overline{\boldsymbol{\beta}}_{w}$ & t-statistic & TWN50 & $\Delta \overline{\boldsymbol{\theta}}_{\boldsymbol{w}}$ & t-statistic & \\
\hline $\mathrm{r} 1$ & 0.2375 & 0.6997 & $\tau 1$ & -1.1292 & $-1.7506^{*}$ & \\
\hline $\mathrm{r} 2$ & -0.2863 & -0.6007 & $\tau 2$ & -4.1877 & $-1.8062^{*}$ & \\
\hline r3 & -0.1894 & -0.6813 & $\tau 3$ & -4.3604 & $-2.4654^{* *}$ & \\
\hline $\mathrm{r} 4$ & -0.0185 & -0.0740 & $\tau 4$ & -4.6591 & $-1.6023^{*}$ & \\
\hline r5 & -0.0028 & -0.0111 & $\tau 5$ & -3.8340 & -1.4412 & \\
\hline r6 & -0.1526 & -0.8129 & $\tau 6$ & -3.3080 & -1.2270 & \\
\hline TM100 & $\Delta \overline{\boldsymbol{\beta}}_{m}$ & t-statistic & TM100 & $\Delta \overline{\boldsymbol{\theta}}_{m}$ & t-statistic & \\
\hline $\mathrm{r} 1$ & 0.3169 & 0.5476 & $\tau 1$ & 1.3202 & 0.9266 & \\
\hline $\mathrm{r} 2$ & 0.7322 & 1.3201 & $\tau 2$ & 2.9998 & 1.4108 & \\
\hline r3 & 0.3160 & 0.7913 & $\tau 3$ & 3.9629 & $1.4867^{*}$ & \\
\hline $\mathrm{r} 4$ & 0.0464 & 0.1137 & $\tau 4$ & 4.6706 & 1.2667 & \\
\hline $\mathrm{r} 5$ & 0.0540 & 0.1481 & $\tau 5$ & 4.6473 & 1.3023 & \\
\hline r6 & 0.2663 & 0.9637 & $\tau 6$ & 4.2398 & 1.2519 & \\
\hline
\end{tabular}

Panels $A$ and B represent analytical tests on the average changes in the co-movement of weighted stock returns and turnover, respectively, for those component stocks excluded from the TWN50 and included in the TM100, or excluded from the TWN50 and included in the TM100 before and after their label changes, from one-month to six-month periods. $\Delta \bar{\beta}_{w}$ and $\Delta \bar{\beta}_{m}$ represent the average change in the co-movement of weighted returns, and $\Delta \bar{\theta}_{w}$ and $\Delta \bar{\theta}_{m}$ represent the average changes in the weighted turnover's co-movement. Subscripts $\mathrm{w}$ and $\mathrm{m}$ respectively represent the TWN50 and TM100. Further, rl represents the test period for weighted stock returns one month before and after the style change; $\tau 1$ represents the test period for weighted stock turnovers one month before and after the style change. Thus, the test period spans one month to six months. ***, **, and * indicate significance at the $1 \%, 5 \%$, and $10 \%$ levels, respectively.

Compared to the overly optimistic sentiment period in Panel A in Table 4, Table 5 illustrates the test results for markets with overly optimistic sentiments. Regardless of stocks' returns and turnover, no difference exists in the direction of switch in co-movement relationships. However, Table 5 illustrates an obviously significant weakened co-movement relationship. Specifically, the co-movement relationship with the original for component stocks excluded from the TWN50 and included in the TM100 index weakened significantly in turnovers and changed insignificantly in returns with the original group. The regression for the co-movement relationship on both returns and turnovers are insignificant with the new group.

The results of optimistic and overly optimistic sentiment suggest that the more optimistic the sentiment is, the more significant the change in co-movement relationships is. 
Table 5: Co-Movement Testing in the Optimistic Market

\begin{tabular}{|c|c|c|c|c|c|c|}
\hline \multicolumn{6}{|c|}{ Panel A: The Component Stocks Excluded from the TM100 and Included in the TWN50 in the Optimistic Market } & \multirow[t]{2}{*}{$\mathrm{n}=6$} \\
\hline TWN50 & $\Delta \overline{\boldsymbol{\beta}}_{w}$ & t-statistic & TWN50 & $\Delta \overline{\boldsymbol{\theta}}_{w}$ & t-statistic & \\
\hline $\mathrm{r} 1$ & 0.3885 & 0.7909 & $\tau 1$ & -0.1955 & -0.6386 & \\
\hline $\mathrm{r} 2$ & 0.5579 & $2.0628^{* *}$ & $\tau 2$ & 0.9300 & $1.8409^{*}$ & \\
\hline r3 & 0.3788 & 1.0739 & $\tau 3$ & 0.4097 & 0.7812 & \\
\hline r4 & 0.0892 & 0.2570 & $\tau 4$ & 1.0966 & $1.6006^{*}$ & \\
\hline $\mathrm{r} 5$ & 0.2127 & 0.6138 & $\tau 5$ & 2.0240 & $2.1739^{* *}$ & \\
\hline r6 & 0.2162 & 0.6184 & $\tau 6$ & 2.6500 & $2.6917^{* *}$ & \\
\hline TM100 & $\Delta \overline{\boldsymbol{\beta}}_{m}$ & t-statistic & TM100 & $\Delta \overline{\boldsymbol{\theta}}_{m}$ & t-statistic & \\
\hline$\overline{\mathrm{r} 1}$ & -0.5683 & -1.2141 & $\tau 1$ & 0.0627 & 0.1403 & \\
\hline $\mathrm{r} 2$ & -0.5018 & $-2.1930^{* *}$ & $\tau 2$ & -0.1129 & -0.3217 & \\
\hline r3 & -0.3790 & -1.4617 & $\tau 3$ & 0.0518 & 0.3041 & \\
\hline r4 & -0.1878 & -0.7497 & $\tau 4$ & -0.4498 & -1.1401 & \\
\hline r5 & -0.2542 & -1.2276 & $\tau 5$ & -0.6296 & -1.4185 & \\
\hline r6 & -0.2307 & -1.1158 & $\tau 6$ & -1.0112 & $-2.0312^{* *}$ & \\
\hline \multicolumn{6}{|c|}{ Panel B: The Component Stocks Excluded from the TWN50 and Included in the TM100 in the Optimistic Market } & $\mathrm{n}=7$ \\
\hline TWN50 & $\Delta \overline{\boldsymbol{\beta}}_{w}$ & t-statistic & TWN50 & $\Delta \overline{\boldsymbol{\theta}}_{w}$ & t-statistic & \\
\hline $\mathrm{r} 1$ & 0.1336 & 0.2838 & $\tau 1$ & -2.4690 & $-1.6703^{*}$ & \\
\hline $\mathrm{r} 2$ & 0.3530 & 1.4746 & $\tau 2$ & -0.6432 & $-1.9902^{* *}$ & \\
\hline r3 & 0.3223 & 1.5981 & $\tau 3$ & -0.5310 & $-2.3370^{* *}$ & \\
\hline $\mathrm{r} 4$ & 0.0573 & 0.2675 & $\tau 4$ & -0.6784 & $-2.2420^{* *}$ & \\
\hline r5 & 0.1012 & 0.4351 & $\tau 5$ & -0.5718 & $-1.6377^{*}$ & \\
\hline r6 & 0.0417 & 0.2150 & $\tau 6$ & -0.6731 & $-1.6689^{*}$ & \\
\hline TM100 & $\Delta \overline{\boldsymbol{\beta}}_{m}$ & t-statistic & TM100 & $\Delta \overline{\boldsymbol{\theta}}_{m}$ & t-statistic & \\
\hline $\mathrm{r} 1$ & 0.0934 & 0.1129 & $\tau 1$ & 1.2434 & 1.2946 & \\
\hline $\mathrm{r} 2$ & 0.0240 & 0.0703 & $\tau 2$ & 0.1399 & 0.6137 & \\
\hline r3 & -0.0754 & -0.3313 & $\tau 3$ & 0.0808 & 0.4375 & \\
\hline $\mathrm{r} 4$ & 0.1427 & 0.5976 & $\tau 4$ & 0.0433 & 0.3928 & \\
\hline $\mathrm{r} 5$ & 0.0643 & 0.3155 & $\tau 5$ & 0.0447 & 0.3316 & \\
\hline r6 & 0.0904 & 0.5560 & $\tau 6$ & 0.1188 & 1.3427 & \\
\hline
\end{tabular}

Panels $A$ and B represent analytical tests on the average changes in the co-movement of weighted stock returns and turnover, respectively, for those component stocks excluded from the TWN50 and included in the TM100, or excluded from the TWN50 and included in the TM100 before and after their label changes, from one-month to six-month periods. $\Delta \bar{\beta}_{w}$ and $\Delta \bar{\beta}_{m}$ represent the average change in the co-movement of weighted returns, and $\Delta \bar{\theta}_{w}$ and $\Delta \bar{\theta}_{m}$ represents the average changes in the weighted turnover's co-movement. Subscripts $\mathrm{w}$ and $\mathrm{m}$ respectively represent the TWN50 and TM100. Further, rl represents the test period for weighted stock returns one month before and after the style change; $\tau 1$ represents the test period for weighted stock turnovers one month before and after the style change. Thus, the test period spans one month to six months. ***, **, and * indicate significance at the $1 \%, 5 \%$, and $10 \%$ levels, respectively.

Tables 6 and 7 illustrate the test results for the pessimistic and overly pessimistic market periods. First, Table 6 reports the results for the pessimistic sentiment market period. With the exception of the insignificant change in co-movement relationships with turnover, regardless of the direction of stock reorganization, the relationships of stock returns and turnover with the original group weakens, but strengthens with the new group. The results are the same as and even more significant than the test results for the bull market. 
Table 6: Co-Movement Testing in the Pessimistic Market

\begin{tabular}{|c|c|c|c|c|c|c|}
\hline \multicolumn{3}{|c|}{ Panel A: The Component Stocks Excluded from the } & \multicolumn{3}{|c|}{ Included in the TWN50 in the Pessimistic Market } & \multirow[t]{2}{*}{$\mathrm{n}=10$} \\
\hline TWN50 & $\Delta \overline{\boldsymbol{\beta}}_{w}$ & t-statistic & TWN50 & $\Delta \overline{\boldsymbol{\theta}}_{w}$ & t-statistic & \\
\hline$\overline{\mathrm{r} 1}$ & 1.2265 & $3.2716^{* * *}$ & $\tau 1$ & 1.1610 & 0.9368 & \\
\hline $\mathrm{r} 2$ & 1.0696 & $4.2541^{* * *}$ & $\tau 2$ & 1.5436 & $2.0888^{* *}$ & \\
\hline r3 & 0.7454 & $4.0011^{* * *}$ & $\tau 3$ & 0.9927 & $2.1908^{* *}$ & \\
\hline r4 & 0.6143 & $3.0974^{* * *}$ & $\tau 4$ & 0.5864 & 1.2172 & \\
\hline r5 & 0.4945 & $2.8302^{* * *}$ & $\tau 5$ & 1.0965 & $2.5274^{* *}$ & \\
\hline r6 & 0.5387 & $3.4712^{* * *}$ & $\tau 6$ & 0.9184 & $2.2981^{* *}$ & \\
\hline TM100 & $\Delta \overline{\boldsymbol{\beta}}_{m}$ & t-statistic & TM100 & $\Delta \overline{\boldsymbol{\theta}}_{\boldsymbol{m}}$ & t-statistic & \\
\hline $\mathrm{r} 1$ & -1.1394 & $-3.2577^{* * *}$ & $\tau 1$ & -0.6975 & -1.1980 & \\
\hline $\mathrm{r} 2$ & -0.9285 & $-3.6345^{* * *}$ & $\tau 2$ & -0.9893 & $-2.7872^{* *}$ & \\
\hline r3 & -0.6359 & $-3.0592^{* * *}$ & $\tau 3$ & -0.8624 & $-2.4587^{* *}$ & \\
\hline $\mathrm{r} 4$ & -0.5481 & $-2.7114^{* *}$ & $\tau 4$ & -0.6284 & $-2.1129^{* *}$ & \\
\hline r5 & -0.4756 & $-2.5437^{* *}$ & $\tau 5$ & -0.9773 & $-3.7885^{* * *}$ & \\
\hline r6 & -0.5229 & $-3.4471^{* * *}$ & $\tau 6$ & -0.9495 & $-3.9963^{* * *}$ & \\
\hline \multicolumn{6}{|c|}{$\begin{array}{l}\text { Panel B: The Component Stocks Excluded from the TWN50 and Included in the TM100 in the Pessimistic Market } \\
\end{array}$} & $\mathrm{n}=10$ \\
\hline TWN50 & $\Delta \overline{\boldsymbol{\beta}}_{w}$ & t-statistic & TWN50 & $\Delta \overline{\boldsymbol{\theta}}_{w}$ & t-statistic & \\
\hline $\mathrm{r} 1$ & -0.7990 & $-1.8239^{*}$ & $\tau 1$ & -0.3953 & -0.3359 & \\
\hline $\mathrm{r} 2$ & -0.3336 & $-1.4955^{*}$ & $\tau 2$ & -0.9605 & -1.2686 & \\
\hline r3 & -0.2445 & -1.3775 & $\tau 3$ & -0.4671 & -0.9225 & \\
\hline r4 & -0.0938 & -0.6965 & $\tau 4$ & -0.9227 & $-2.7561^{* *}$ & \\
\hline r5 & -0.0331 & -0.2885 & $\tau 5$ & -0.0276 & -0.0945 & \\
\hline r6 & -0.2365 & $-1.9923^{* *}$ & $\tau 6$ & 0.3023 & 0.9658 & \\
\hline TM100 & $\Delta \overline{\boldsymbol{\beta}}_{m}$ & t-statistic & TM100 & $\Delta \overline{\boldsymbol{\theta}}_{\boldsymbol{m}}$ & t-statistic & \\
\hline $\mathrm{r} 1$ & 0.6228 & 1.0686 & $\tau 1$ & 0.2879 & 1.2090 & \\
\hline $\mathrm{r} 2$ & 0.1497 & 0.4542 & $\tau 2$ & 0.4230 & $1.4635^{*}$ & \\
\hline r3 & 0.1526 & 0.6303 & $\tau 3$ & 0.3890 & 1.2241 & \\
\hline $\mathrm{r} 4$ & 0.0735 & 0.4248 & $\tau 4$ & 0.5864 & $1.5316^{*}$ & \\
\hline r5 & 0.0485 & 0.4370 & $\tau 5$ & 0.0881 & 0.3509 & \\
\hline r6 & 0.2324 & $1.9922^{* *}$ & $\tau 6$ & -0.0786 & -0.3390 & \\
\hline
\end{tabular}

Panels $A$ and B represent analytical tests on the average changes in the co-movement of weighted stock returns and turnover, respectively, for those component stocks excluded from the TWN50 and included in the TM100, or excluded from the TWN50 and included in the TM100 before and after their label changes, from one-month to six-month periods. $\Delta \bar{\beta}_{w}$ and $\Delta \bar{\beta}_{m}$ represent the average change in the co-movement of weighted returns, and $\Delta \bar{\theta}_{w}$ and $\Delta \bar{\theta}_{m}$ represents the average changes in the weighted turnover's co-movement. Subscripts $\mathrm{w}$ and $\mathrm{m}$ respectively represent the TWN50 and TM100. Further, r1 represents the test period for weighted stock returns one month before and after the style change; $\tau 1$ represents the test period for weighted stock turnovers one month before and after the style change. Thus, the test period spans one month to six months. ***, $* *$, and $*$ indicate significance at the $1 \%, 5 \%$, and $10 \%$ levels, respectively.

However, compared to Table 6, Table 7 reveals that the change in co-movement relationships regarding turnover are insignificant for the overly pessimistic market period. Moreover, the relationship with the new group weakens, and strengthens with the original group, as the component stock moves from the TM100 to the TWN50. This result contradicts those in the other tables. The group with the same label will demonstrate a strengthened co-movement relationship with the original group and a weakened link with the new group. Consequently, Boyer's (2011) label co-movement theory is not valid during overly pessimistic market periods. 
Table 7: Co-Movement Testing in the Overly Pessimistic Market

\begin{tabular}{|c|c|c|c|c|c|}
\hline \multicolumn{6}{|c|}{ Panel A: The Component Stocks Excluded from the TM100 and Included in the TWN50 in the Overly Pessimistic Market $n=2$} \\
\hline TWN50 & $\Delta \overline{\boldsymbol{\beta}}_{w}$ & t-statistic & TWN50 & $\Delta \overline{\boldsymbol{\theta}}_{w}$ & t-statistic \\
\hline $\mathrm{r} 1$ & -1.6466 & -2.6434 & $\tau 1$ & -1.8295 & $-10.6154^{* *}$ \\
\hline $\mathrm{r} 2$ & -1.2464 & -2.4609 & $\tau 2$ & 0.6555 & 0.3739 \\
\hline r3 & -1.0936 & -2.2212 & $\tau 3$ & 1.2993 & 0.7535 \\
\hline $\mathrm{r} 4$ & -0.7097 & $-4.3324^{*}$ & $\tau 4$ & 1.1917 & 0.6687 \\
\hline r5 & -0.3488 & $-3.2079^{*}$ & $\tau 5$ & 1.1157 & 0.7572 \\
\hline r6 & -0.1688 & -1.2144 & $\tau 6$ & 0.2971 & 0.4931 \\
\hline TM100 & $\Delta \overline{\boldsymbol{\beta}}_{m}$ & t-statistic & TM100 & $\Delta \overline{\boldsymbol{\theta}}_{m}$ & t-statistic \\
\hline $\mathrm{r} 1$ & 1.6855 & $5.3821^{*}$ & $\tau 1$ & 1.2833 & 2.3476 \\
\hline $\mathrm{r} 2$ & 1.4044 & $4.0879^{*}$ & $\tau 2$ & -0.1235 & -0.1946 \\
\hline r3 & 1.1920 & $3.1826^{*}$ & $\tau 3$ & -0.4792 & -0.7870 \\
\hline $\mathrm{r} 4$ & 0.8283 & $3.3161^{*}$ & $\tau 4$ & -0.4089 & -0.6088 \\
\hline $\mathrm{r} 5$ & 0.5449 & 2.7029 & $\tau 5$ & -0.3100 & -0.6896 \\
\hline r6 & 0.3722 & 1.7147 & $\tau 6$ & -0.5721 & -0.9563 \\
\hline \multicolumn{6}{|c|}{ Panel B: The Component Stocks Excluded from the TWN50 and Included in the TM100 in the Overly Pessimistic Market $\mathrm{n}=2$} \\
\hline TWN50 & $\Delta \overline{\boldsymbol{\beta}}_{w}$ & t-statistic & TWN50 & $\Delta \overline{\boldsymbol{\theta}}_{w}$ & t-statistic \\
\hline $\mathrm{r} 1$ & 1.0499 & 0.7454 & $\tau 1$ & -0.7166 & -1.3550 \\
\hline $\mathrm{r} 2$ & 0.5248 & 0.7106 & $\tau 2$ & -0.9925 & $-5.6778^{*}$ \\
\hline r3 & 0.1826 & 0.3028 & $\tau 3$ & -0.3729 & -0.6642 \\
\hline $\mathrm{r} 4$ & -0.1329 & -0.1525 & $\tau 4$ & -0.4024 & $-12.0754^{* *}$ \\
\hline $\mathrm{r} 5$ & -0.0035 & -0.0049 & $\tau 5$ & -0.3211 & -2.2612 \\
\hline r6 & 0.0707 & 0.1245 & $\tau 6$ & 0.6725 & 1.1350 \\
\hline TM100 & $\Delta \overline{\boldsymbol{\beta}}_{m}$ & t-statistic & TM100 & $\Delta \overline{\boldsymbol{\theta}}_{m}$ & t-statistic \\
\hline $\mathrm{r} 1$ & -0.6336 & -0.4497 & $\tau 1$ & 0.2852 & 1.9939 \\
\hline $\mathrm{r} 2$ & -0.1643 & -0.2575 & $\tau 2$ & 0.8481 & 0.9068 \\
\hline r3 & -0.1905 & -0.2365 & $\tau 3$ & 0.8127 & 0.7869 \\
\hline $\mathrm{r} 4$ & 0.0897 & 0.1001 & $\tau 4$ & 0.6581 & 1.2347 \\
\hline $\mathrm{r} 5$ & 0.0012 & 0.0016 & $\tau 5$ & 0.3629 & 0.9985 \\
\hline r6 & 0.0345 & 0.0584 & $\tau 6$ & 0.6360 & 0.9461 \\
\hline
\end{tabular}

Panels $A$ and $B$ represent analytical tests on the average changes in the co-movement of weighted stock returns and turnover, respectively, for those component stocks excluded from the TWN50 and included in the TM100, or excluded from the TWN50 and included in the TM100 before and after their label changes, from one-month to six-month periods. $\Delta \bar{\beta}_{w}$ and $\Delta \bar{\beta}_{m}$ represent the average change in the co-movement of weighted returns, and $\Delta \bar{\theta}_{w}$ and $\Delta \bar{\theta}_{m}$ represent the average changes in the weighted turnover's co-movement. Subscripts $\mathrm{w}$ and $\mathrm{m}$ respectively represent the TWN50 and TM100. Further, r1 represents the test period for weighted stock returns one month before and after the style change; $\tau 1$ represents the test period for weighted stock turnovers one month before and after the style change. Thus, the test period spans one month to six months. ***, $* *$, and $*$ indicate significance at the $1 \%, 5 \%$, and $10 \%$ levels, respectively.

\section{CONCLUSION}

We studied ETF component stocks in Taiwan's stock market to investigate the changes in the co-movement relationships of both stock returns and turnover. These changes relate to the original and new groups, both before and after reorganization with either TWN50 inclusion and TM100 exclusion, or TM100 inclusion and TWN50 exclusion. Overall, the results parallel Boyer's (2011) label co-movement theory, in that the co-movement relationship with the new group strengthens after the label change and weakens with the original group, regardless of stock returns or turnover. However, a detailed analysis reveals that this result is indeed insignificant in the component stocks excluded from the TWN50 and included in the TM100. Additionally, we find a co-movement relationship in turnover, which Boyer (2011) does not discuss. 
We find a slight difference in the co-movement relationships in bull and bear market periods. In bear markets, there is an insignificant co-movement relationship with exclusion from the TM100 and inclusion in the TWN50, but significant co-movement relationships with exclusion from the TWN50 and inclusion in the TM100. Regarding investors' sentiment, in overly optimistic markets, the returns and turnover of comovement relationship in both bear and bull markets are still significant and similar, although the significance decreases. However, during optimistic periods, the results of both returns and turnover comovement relationships do not differ in direction, and during overly optimistic periods, decrease in significance. The result suggests that during overly optimistic sentiment periods, the switch of comovement relationships is more significant.

For market periods with pessimistic sentiment, our results indicate that besides insignificant changes in comovement relationships with turnover, stock returns and turnover show weaker relationships with the original group, and stronger relationships with the new group. These results are similar to those for bull markets and are even more significant. However, for overly pessimistic periods, the switch of co-movement relationship with turnover is insignificant. The co-movement relationship with the new group weakens, but strengthens with the original group when component stocks are excluded from the TM100 and included in the TWN50. This result is inconsistent with Boyer's (2011) label co-movement theory, which demonstrates a strengthened co-movement relationship with the original group and a weakened co-movement relationship with the new group. This is because of investors' overreactions under anxious sentiment. However, the sample size in the overly pessimistic period is small, and therefore, we need more representative samples for further verification.

\section{REFERENCES}

Armstrong, J. S. and R. Fildes (1984) “Judgment under Uncertainty: Heuristics and Biases," Journal of Forecasting, vol. 3(2), p. 235-39.

Barberis, N. and A. Shleifer (2003) “Style Investing," Journal of Financial Economics, vol. 68(2), p. 16199.

Barberis, N., A. Shleifer and J. Wurgler (2005) “Comovement," Journal of Financial Economics, vol. 75(2), p. 283-317.

Becker, J. and D. Kuhn (1984) "Judgements under Uncertainty: Heuristics and Biases," New Ideas in Psychology, vol. 2(2), p. 201-10.

Boussaidi, R. (2013) "Representativeness Heuristic, Investor Sentiment and Overreaction to Accounting Earnings: The Case of the Tunisian Stock Market," Procedia-Social and Behavioral Sciences, vol. 81, p. $9-21$.

Boyer, B. H. (2011) "Style-Related Comovement: Fundamentals or Labels?” The Journal of Finance, vol. 66(1), p. 307-32.

Brockman, P., I. Liebenberg and M. Schutte (2010) "Comovement, Information Production, and the Business Cycle,” Journal of Financial Economics, vol. 97(1), p. 107-29.

Chen, T. H. and H. C. Chou. (2014) "Financial Risk Management Tools, Measurement and Future Development," $3^{\text {rd }}$ ed., p. 486-97, Taipei: Yeh Yeh Book Gallery.

Claessens, S. and Y. Yafeh (2012) "Comovement of Newly Added Stocks with National Market Indices: Evidence from around the World," Review of Finance, vol. 17(1), p. 203-27. 
Fabozzi, F. J. and J. C. Francis (1979) "Mutual Fund Systematic Risk for Bull and Bear Markets: An Empirical Examination," The Journal of Finance, vol. 34(5), p. 1243-50.

Froot, K. A. and E. M. Dabora (1999) "How Are Stock Prices Affected by the Location of Trade?" Journal of Financial Economics, vol. 53(2), p. 189-216.

Greenwood, R. (2005) "Short- and Long-Term Demand Curves for Stocks: Theory and Evidence on the Dynamics of Arbitrage," Journal of Financial Economics, vol. 75(3), p. 607-49.

Greenwood, R. M. and N. Sosner (2007) "Trading Patterns and Excess Comovement of Stock Returns," Financial Analysts Journal, vol. 63(5), p. 69-81.

Höchstötter, M., S. Meyer, R. Riordan and A. Storkenmaier (2014) "International Stock Market Comovement and News,” Journal of Financial Research, vol. 37(4), p. 519-42.

Harris, L. and E. Gurel (1986) "Price and Volume Effects Associated with Changes in the S\&P 500 List: New Evidence for the Existence of Price Pressures," The Journal of Finance, vol. 41(4), p. 815-29.

Jin, L. and S. C. Myers (2006) "R2 around the World: New Theory and New Tests," Journal of Financial Economics, vol. 79(2), p. 257-92.

Kahneman, D. and A. Tversky (1979) "Prospect Theory: An Analysis of Decision under Risk," Econometrica: Journal of the econometric society, vol. 47(2), p. 263-91.

Kaul, A., V. Mehrotra and R. Morck (2000) "Demand Curves for Stocks Do Slope Down: New Evidence from an Index Weights Adjustment," The Journal of Finance, vol. 55(2), p. 893-912.

Kumar, A. and C. Lee (2006) "Retail Investor Sentiment and Return Comovements," The Journal of Finance, vol. 61(5), p. 2451-86.

Kumar, A., J. K. Page and O. G. Spalt (2016) "Gambling and Comovement," Journal of Financial and Quantitative Analysis, vol. 51(1), p. 85-111.

Liu, H. and S. Du (2016) "Can an Overconfident Insider Coexist with a Representativeness Heuristic Insider?” Economic Modelling, vol. 54, p. 170-77.

Luo, G. Y. (2013) "Can Representativeness Heuristic Traders Survive in a Competitive Securities Market?" Journal of Financial Markets, vol. 16(1), p. 152-64.

Lynch, A. W. and R. R. Mendenhall (1997) "New Evidence on Stock Price Effects Associated with Charges in the S\&P 500 Index," Journal of Business, vol. 70(3), p. 351-83.

Muslu, V., M. Rebello and Y. Xu (2014) "Sell-Side Analyst Research and Stock Comovement," Journal of Accounting Research, vol. 52(4), p. 911-54.

Pirinsky, C. and Q. Wang (2006) "Does Corporate Headquarters Location Matter for Stock Returns?" The Journal of Finance, vol. 61(4), p. 1991-2015.

Shleifer, A. (1986) "Do Demand Curves for Stocks Slope Down?" The Journal of Finance, vol. 41(3), p. 579-90. 
Veldkamp, L. L. (2006) "Information Markets and the Comovement of Asset Prices," The Review of Economic Studies, vol. 73(3), p. 823-45.

Vijh, A. M. (1994) "S\&P 500 Trading Strategies and Stock Betas," The Review of Financial Studies, vol. 7(1), p. 215-51.

Wurgler, J. and E. Zhuravskaya (2002) "Does Arbitrage Flatten Demand Curves for Stocks?" The Journal of Business, vol. 75(4), p. 583-608.

\section{ACKNOWLEDGEMENTS}

The authors thank Terrance Jalbert, Editor-in-Chief of the Institute for Business and Finance Research (IBFR), and an anonymous referee for their helpful comments.

\section{BIOGRAPHY}

Chun-An Li is Professor of Finance at the National Yunlin University of Science \& Technology in Taiwan. His research appears in journals such as International Review of Economics and Finance, The International Journal of Business and Finance Research, Investment management and Financial Innovations, The Empirical Economics Letters, Applied Financial Economics, Emerging Markets Finance and Trade, Journal of Financial Studies, and Review of Pacific Basin Financial Markets and Polices. He can be reached at National Yunlin University of Science \& Technology, No. 123, Sec. 3, University Rd. Douliu, Yunlin 64002, Taiwan, R.O.C., liica@tuntech.edu.tw.

Min-Ching Lee is a doctoral candidate at the National Yunlin University of Science. Her research interests include co-movement, contagion, and propagation of financial markets. She can be reached at Department of Finance, National Yunlin University of Science and Technology, No. 123, Sec. 3, University Road, Douliu, Yunlin 64002, Taiwan, R.O.C., D10124002@yuntech.edu.tw.

Ju-Hua Liu is the Writing Coordinator at the National Yunlin University of Science. She can be reached at Department of Finance, National Yunlin University of Science and Technology, No. 123, Sec. 3, University Road, Douliu, Yunlin 64002, Taiwan R.O.C., luhua-liou566@yahoo.com.tw. 